\title{
Effects of Heat Processing Time on Total Phenolic Content and Antioxidant Capacity of Ginseng Jung Kwa
}

\author{
Chang-Ho Oh, Gyo-Nam Kim, Sang-Hyun Lee, Jung-Sook Lee, and Hae-Dong Jang* \\ Department of Food and Nutrition, Hannam University, Daejeon 305-811, Korea
}

Korean ginseng (Panax ginseng C.A. Meyer) preserved in syrup, known as ginseng Jung Kwa (GJK), is a popular traditional snack in Korea. We investigated the effects of heat processing time on total phenolic content and antioxidant capacity of GJK. Water extract was prepared from GJK with different heat processing times, 3 hours (GJK-3), 6 hours (GJK6), or 12 hours (GJK-12), with sonication for 2 hours. The GJK extract contained total phenolic content in the following order: GJK-12 (2.28\%)> GJK-6 (1.57\%)> GJK-3 (1.29\%). Both the peroxy and hydroxyl radical-scavenging activity and cellular antioxidant capacity of GJK extract was significantly enhanced with increasing heat processing time. The hydroxyl radicalscavenging activity of GJK-12 extract was greater than that of the GJK-3 and GJK-6 extracts, consistent with metal chelating capacity and reducing capacity. In a cellular model, the GJK extract effectively reduced 2,2'-azobis(2-amidinopropane) dihydrochloride, $\mathrm{Cu}^{2+}$-, and $\mathrm{H}_{2} \mathrm{O}_{2}$-induced oxidative stress, with GJK-12 and GJK-6 extracts demonstrating greater cellular antioxidant capacity than the GJK-3 extract. These results suggest that heat processing time can contribute to the antioxidant capacity of GJK and that GJK extract may have the potential to be used as an effective dietary antioxidant to prevent oxidative stress-related diseases.

Keywords: Korean ginseng Jung Kwa, Total phenolic content, Antioxidant capacity, Oxygen radical absorbance capacity

\section{INTRODUCTION}

Reactive oxygen species (ROS) are broadly defined as oxygen-containing, highly reactive species. They are essential for biological functions and are constantly generated during cellular metabolism. A moderate increase in ROS can act as an intracellular messenger in cellular events, whereas excessive production of ROS can cause oxidative stress and damage to biological molecules [1]. The term "oxidative stress" refers to an imbalance between ROS generation and antioxidant defense activity. Severe oxidative stress plays a role in chronic diseases, including cancer and coronary heart disease [2]. Thus, maintaining antioxidant homeostasis is crucial for normal cell growth and survival.
Korean ginseng (Panax ginseng C.A. Meyer) is cultivated in Asian countries and is one of the most widely used medicinal herbs in the world. Multiple biological activities of Korean ginseng have been reported, such as anti-oxidant, anti-diabetic, and anti-carcinogenic activities, in many experimental systems [3,4]. Korean ginseng is processed into a wide range of products, including teas, beverages, snacks, jellies, and candy. Korean ginseng preserved in syrup, known as ginseng Jung Kwa (GJK), is a popular traditional snack in Korea. It has been reported that repeated rounds of heat processing [5], different soaking time in syrup [6], and the amount of honey [7] may contribute to the quality characteristics of GJK. (c) This is an Open Access article distributed under the terms of the Creative Commons Attribution Non-Commercial License (http://creativecommons.org/licenses/by-nc/3.0/) which permits unrestricted non-commercial use, distribution, and reproduction in any medium, provided the original work is properly cited.
Received 22 Apr. 2010, Revised 3 Jun. 2010, Accepted 6 Jul. 2010

*Corresponding author

E-mail: haedong@hnu.kr

Tel: +82-42-629-8795, Fax: +82-42-629-8805 
Korean red ginseng (KRG), another heat-processed ginseng product, has various biological effects, including anti-oxidant activity, and anti-diabetic, anti-tumor, and anti-stress effects [8-10]. During steaming and drying, various chemical components of Korean red ginseng undergo a non-enzymatic browning reaction, known as the Maillard reaction $[8,11]$. Polyphenols are oxidized during this browning reaction and the oxidation creates more active forms of polyphenols [12].

Polyphenols, which are abundant in fruits, vegetables, and grains, have been proposed to be a major source of dietary anti-oxidants. Many studies have suggested that the anti-oxidant activity is proportional to total phenolic content. Recently, it was shown that heat processing of ginseng contributed to an increase in total phenolic content [13]. Thus, these observations suggest that heat processing may contribute to the anti-oxidant activity of GJK.

This study examined the effects of heat processing time on total phenolic content and anti-oxidant capacity of GJK in an in vitro and cellular anti-oxidant model. Further, to what extent heat processing contributes to anti-oxidant activity of GJK is discussed.

\section{MATERIALS AND METHODS}

\section{Materials}

Four-year Korean ginseng was purchased from a local market in Geumsan, Korea. Grain syrup (Jo Chung) was obtained from Shindoan Food Co. (Gyeryong, Korea). 2,2'-azobis (2-amidinopropane) dihydrochloride (AAPH) was obtained from Wako Pure Co. (Osaka, Japan). Dulbecco's modified Eagle's medium, fetal bovine serum, and Hank's balanced salt solution (HBSS) were purchased from Gibco BRL (Carlsbad, CA, USA). The HepG2 cell line was obtained from American Type Culture Collection (Rockville, MD, USA). Unless noted, all other chemicals were purchased from Sigma Co. (St. Louis, MO, USA).

\section{Preparation of ginseng Jung Kwa extracts}

Washed 4-year Korean ginseng was peeled and a hole was bored using a needle. Ginseng was boiled for 3, 6 , and 12 hours with grain syrup containing glucose (grain syrup, 83\%; glucose, 17\%) using a Darim CR-3001C (C $\&$ Electronics, Yeoju, Korea) at $100^{\circ} \mathrm{C}$. GJK was dried for 2 days at room temperature and then ground. Ground GJK (50 g) was extracted by sonication (Branson, Danbury, CT, USA) at $25^{\circ} \mathrm{C}$ for 2 hours with $500 \mathrm{~mL}$ of distilled water. GJK water extract was freeze-dried and kept at $-20^{\circ} \mathrm{C}$ until analysis.

\section{Determination of total phenolic content}

Total phenolic content of the GJK extract was determined using a modified Folin-Ciocalteu method [14]. GJK extract $(1 \mathrm{~mL})$ was dissolved in distilled water and mixed with $1 \mathrm{~mL}$ of ethanol $(95 \%, \mathrm{v} / \mathrm{v})$ in a test tube. Distilled water $(5 \mathrm{~mL})$ and Folin-Ciocalteu reagent $(0.5 \mathrm{~mL})$ was also added to each test tube. The reaction mixture stood for 5 minutes. Then, $\mathrm{Na}_{2} \mathrm{CO}_{3}$ solution $(1 \mathrm{~mL})$ was added into the test tubes and the reaction mixture stood in the dark for 1 hour. The absorbance was measured at $725 \mathrm{~nm}$ with ethanol $(95 \%, \mathrm{v} / \mathrm{v})$ as a blank.

\section{Oxygen radical absorbance capacity assay}

The peroxyl and hydroxyl radical-scavenging capacities of GJK extract were estimated using the oxygen radical absorbance capacity (ORAC) assay. Fluorescein $(40 \mathrm{nM} ; 100 \mu \mathrm{L})$ in $75 \mathrm{mM}$ potassium phosphate buffer ( $\mathrm{pH}$ 7.4) was added in triplicate to wells of a black, 96-well microplate. The fluorescein solution contained $0.0125 \%(\mathrm{v} / \mathrm{v})$ acetone. A volume of $50 \mu \mathrm{L}$ of blank, Trolox standard, or sample (400 and $800 \mu \mathrm{g} / \mathrm{mL}$ ) in $75 \mathrm{mM}$ potassium phosphate buffer ( $\mathrm{pH}$ 7.4) was added to each well. AAPH $(80 \mathrm{mM} ; 50 \mu \mathrm{L})$ in potassium phosphate buffer (pH 7.4) was added to each well as a peroxyl radical generator. Fluorescein was used as a target of free radical attack, with AAPH $(20 \mathrm{mM})$ as a peroxyl radical generator in the peroxyl radical-scavenging capacity $\left(\mathrm{ORAC}_{\mathrm{ROo}}\right.$ ) assay [15] or $\mathrm{H}_{2} \mathrm{O}_{2}-\mathrm{CuSO}_{4}\left(\mathrm{H}_{2} \mathrm{O}_{2}\right.$, $\left.0.75 \% ; \mathrm{CuSO}_{4}, 5 \mu \mathrm{M}\right)$ as a hydroxyl radical generator in the hydroxyl radical scavenging capacity $\left(\mathrm{ORAC}_{\mathrm{OH}}\right)$ assay [16]. AAPH, $\mathrm{CuSO}_{4}, \mathrm{H}_{2} \mathrm{O}_{2}$, and Trolox were prepared fresh daily. Fluorescein fluorescent intensity was measured every 2 minutes and was expressed relative to the initial reading. Final results were calculated based on the difference in the area under the fluorescence decay curve between the blank and each sample. $\mathrm{ORAC}_{\mathrm{ROO}}$. and $\mathrm{ORAC}_{\mathrm{HO}}$. results are expressed as $\mu \mathrm{M}$ of Trolox equivalent (TE). One ORAC unit is equivalent to the net protection area provided by $1 \mu \mathrm{M}$ Trolox.

\section{Metal chelating activity}

The metal chelating activity of GJK extract was assessed by the method of Argirova and Ortwerth [17] with slight modification. GJK extract $(400 \mu \mathrm{g} / \mathrm{mL}$; $200 \mu \mathrm{L}$ ) was mixed with $200 \mu \mathrm{L}$ of $0.1 \mu \mathrm{M} \mathrm{CuSO}_{4}$. Then, $100 \mu \mathrm{L}$ of the GJK extract-CuSO${ }_{4}$ mixture was mixed with $100 \mu \mathrm{L}$ of calcein solution. The fluorescence 
intensity of the final mixture was measured using a Tecan GENios multi-functional plate reader (Tecan, Salzburg, Austria) with fluorescent filters (excitation wavelength, $485 \mathrm{~nm}$; emission filter, $535 \mathrm{~nm}$ ) and compared with the fluorescence intensity of the control, which contained only calcein.

\section{Reducing capacity}

The reducing capacity of the GJK extract was assessed by the method of Aruoma et al. [18] with slight modification. GJK extract $(500 \mu \mathrm{g} / \mathrm{mL} ; 40 \mathrm{~mL})$ in distilled water was mixed with $160 \mu \mathrm{L}$ of a mixture containing $0.5 \mathrm{mM} \mathrm{CuCl}_{2}$ and $0.75 \mathrm{mM}$ neocuproine in $10 \mathrm{mM}$ phosphate buffer ( $\mathrm{pH}$ 7.4). Absorbance was measured at $454 \mathrm{~nm}$ with an ELISA reader over 1 hour. Increased absorbance of the reaction mixture indicated increased reducing capacity.

\section{Evaluation of cytotoxicity}

The potential cytotoxicity of GJK extract on HepG2 cells was determined by the 3-(4,5-dimethylthiazol-2,5diphenyltetrazolium) bromide (MTT) assay. HepG2 cells were seeded at a density of $5 \times 10^{5}$ cells $/ \mathrm{mL}$ in a 12-well plate, incubated for 24 hours, and pretreated with different concentrations of GJK extract. After a 4-hour incubation, MTT reagent was added to each well and incubated at $37^{\circ} \mathrm{C}$ for an additional hour. The medium was removed and the cells were washed with phosphate-buffered saline (PBS, pH 7.4). The intracellular insoluble formazan was dissolved in DMSO. The absorbance of each well was then measured at $570 \mathrm{~nm}$ using an ELISA reader. Cell viability was expressed as the percentage difference between untreated cells and cells treated with GJK extract at the indicated concentrations.

\section{Cellular antioxidant capacity against AAPH- induced oxidative stress in HepG2 cells}

Cellular antioxidant capacity of GJK extract was evaluated in AAPH-induced HepG2 cells using DCFHDA [19], a well-established fluorescent probe used to detect and quantify intracellular ROS. DCFH-DA is transported across the cell membrane and enzymatically deacetylated by intracellular esterases to a nonfluorescent form, DCFH, which is further oxidized by ROS to form the highly fluorescent DCF. HepG2 cells were seeded at a density of $5 \times 10^{5}$ cells $/ \mathrm{mL}$ in a $96-$ well plate. At 24 hours after seeding, the cells were incubated with $1 \mathrm{mg} / \mathrm{mL}$ GJK extract for 30 minutes. The media was removed and cells were gently washed twice with PBS. Instead of media, HBSS, which is stable to fluorescence, was added to each well. AAPH was used as an inducer of peroxyl radical oxidative stress, and $\mathrm{Cu}^{2+}$ and $\mathrm{H}_{2} \mathrm{O}_{2}$ were used as additional inducers of oxidative stress. After wells were treated with $60 \mu \mathrm{M}$ AAPH, $20 \mu \mathrm{M} \mathrm{Cu}^{2+}$, or $100 \mu \mathrm{M} \mathrm{H}_{2} \mathrm{O}_{2}$ for 30 minutes, DCFH-DA was added to the culture plates at a final concentration of $40 \mu \mathrm{M}$ and incubated for 30 minutes at $37^{\circ} \mathrm{C}$ in the dark. DCF fluorescent intensity was measured at an excitation wavelength of $485 \mathrm{~nm}$ and an emission wavelength of $535 \mathrm{~nm}$ using a Tecan GENios fluorometric plate reader.

\section{Statistical analysis}

All data are presented as the mean \pm SD of three experiments. Statistical analysis was carried out using the SPSS (SPSS Inc., Chicago, IL, USA). Analysis of variance (ANOVA) was performed and Duncan's test was used to examine statistically significant differences. A $p$-values $<0.05$ were deemed to indicate statistical significance.

\section{RESULTS AND DISCUSSION}

\section{Extraction yield and total phenolic content}

The extraction yield and total phenolic content of GJK extract are shown in Table 1. The extraction yield of the GJK-12 extract was $39.59 \%$, followed by the GJK-6 (37.72\%) and GJK-3 (32.02\%) extracts. This suggests that the extraction yield of GJK extract increased with increasing heat processing time, due to the release of water-extractable compounds, which may have been produced through the Maillard reaction during heat processing. The total phenolic content of GJK extract increased significantly with increasing heat processing time. The GJK-12 extract had the highest total phenolic content $(2.28 \%)$, followed by the GJK$6(1.57 \%)$ and GJK-3 extracts (1.29\%). The increase in

Table 1. Changes of extraction yield and total phenolic content of ginseng Jung Kwa extract with increase of heat-processing time

\begin{tabular}{ccc}
\hline Ginseng Jung $\mathrm{Kwa}^{1)}$ & $\begin{array}{c}\text { Extraction yields } \\
(\%, \text { w/w-dry base })\end{array}$ & $\begin{array}{c}\text { Total phenolic content } \\
(\%, \text { w/w-extract })\end{array}$ \\
\hline GJK-3 & $32.02 \pm 1.15$ & $1.29 \pm 0.03^{\mathrm{a}}$ \\
GJK-6 & $37.72 \pm 1.22$ & $1.57 \pm 0.08^{\mathrm{b}}$ \\
GJK-12 & $39.59 \pm 1.57$ & $2.28 \pm 0.05^{\mathrm{c}}$
\end{tabular}

The results represent the means \pm SD of values obtained from three experiments.

Different corresponding letters indicate significant differences at $p<0.05$ by Duncan's test.

${ }^{1)} \mathrm{GJK}$ was made by different heat-processing times, GJK-3, GJK-6, and GJK-12. 
total phenolic content in the GJK extract with heat processing was consistent with previous reports using Korean or American ginseng [13,20]. The phenolic content of American ginseng increased with heat processing, which may result from the release of bound phenolic acids linked with glucosides or amine functionalities and an increase in Maillard reaction products (MRPs) by heat processing [13]. An increase in phenolic content, such as maltol and phenolic acids, with heat processing was found in KRG, when compared with white ginseng [20]. Thus, the enhancement in total phenolic content of GJK extract by heat processing may be due to an increase in free and conjugated phenolic acid and maltol content, due to the release of bound phenolic acid and maltol by heat processing and/or increased MRPs.

\section{In vitro antioxidant capacity of ginseng Jung Kwa extract}

The in vitro anti-oxidant capacity of GJK extract was evaluated using the ORAC assay, a widely accepted method to assess the anti-oxidant activity in nutraceutical and pharmaceutical foods $[21,22]$. Fig. 1 demonstrates that the scavenging activity of GJK extract on peroxyl radicals generated by AAPH was concentration-dependent between 100 and $200 \mu \mathrm{g} / \mathrm{mL}$. GJK-12 extract exhibited the highest $\mathrm{ORAC}_{\mathrm{ROO}}$. value $(14.7 \mathrm{TE})$ at $100 \mu \mathrm{g} / \mathrm{mL}$, followed by GJK-6 (8.1 TE) and GJK3 (4.9 TE). The peroxyl radical-scavenging activity of the GJK extract was proportional to the increase in total phenolic content due to heat processing. Many studies have revealed that the phenolic content of plants can

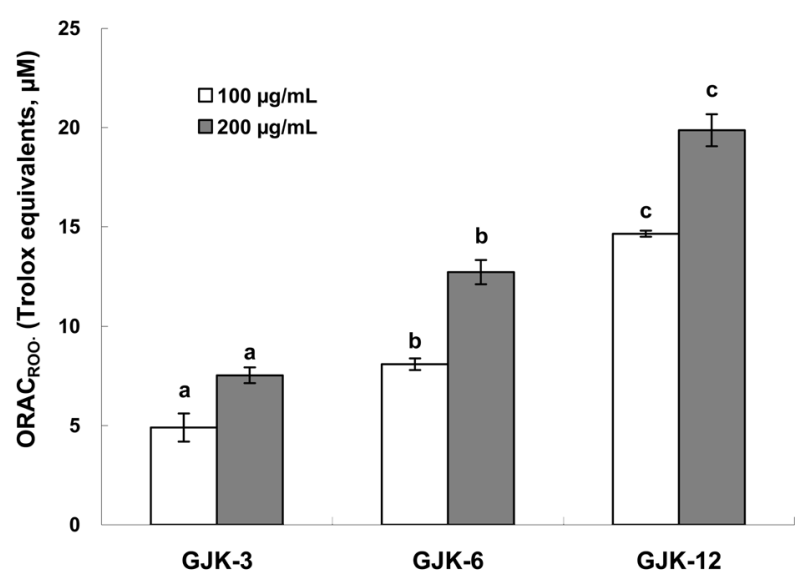

Fig. 1. Effect of heat processing time on peroxyl radical-scavenging activity of GJK extract. GJK was made using different heat processing times: GJK-3, GJK-6, and GJK-12. Each bar represents the mean \pm SD of values obtained from three experiments. Different corresponding letters indicate significant differences at $p<0.05$ by Duncan's test. ORAC $C_{\text {Roo., }}$ peroxyl radical-scavenging capacity. be correlated with their anti-oxidant activities [13,23]. These results indicate that the enhanced peroxyl radicalscavenging activity of GJK extract with the increase in heat processing time may be attributed to the increase in total phenolic content by heat processing.

The ORAC assay system has been successfully used to determine reaction capacity with hydroxyl radicals, highly reactive oxygen species with a short half-life [24]. Hydroxyl radicals are generated through the $\mathrm{H}_{2} \mathrm{O}_{2}$ $\mathrm{Cu}^{2+}$ reaction in the $\mathrm{ORAC}_{\mathrm{OH}}$. system. We previously reported two crucial factors in the $\mathrm{ORAC}_{\mathrm{HO}}$. system: chelating activity for transition metal ions and scavenging activity for the hydroxyl radical itself $[25,26]$.

Hydroxyl radical-scavenging activity of GJK extract increased concentration-dependently between 100 and $200 \mu \mathrm{g} / \mathrm{mL}$ (Fig. 2). ORAC HO $_{\text {. }}$ of GJK extract increased with the increase in heat processing time, from $0.3 \mathrm{TE}$ (GJK-3) to $6.1 \mathrm{TE}$ (GJK-12) at $100 \mu \mathrm{g} / \mathrm{mL}$. The metal chelating activity of GJK extract was determined by measuring the percentage of calcein- $\mathrm{Cu}^{2+}$ complex formation inhibited in the presence of GJK extract. As shown in Table 2, the metal chelating activity of GJK extract at $100 \mu \mathrm{g} / \mathrm{mL}$ was in the order: GJK-12 $(56.7 \%) \geq$ GJK-6 (54.0\%) $\geq$ GJK-3 (47.0\%). The reduction of copper (II) to copper (I) was used to evaluate the reducing capacity of the GJK extract. The reducing capacity of the GJK extract increased, from 2.10 (GJK3) to $8.81(\mathrm{GJK}-12)$ with the increase in heat processing time at $100 \mu \mathrm{g} / \mathrm{mL}$. These results indicate that the enhanced hydroxyl radical-scavenging activity of GJK extracts with increasing heat processing time may be closely related with increased metal chelating capacity

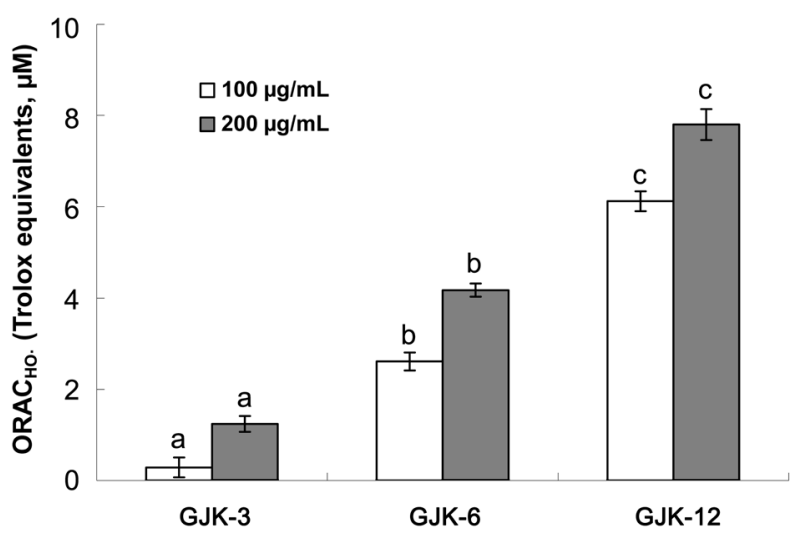

Fig. 2. Effect of heat processing time on hydroxyl radical-scavenging activity of GJK extract. GJK was made using different heat processing times: GJK-3, GJK-6, and GJK-12. Each bar represents the mean \pm SD of values obtained from three experiments. Different corresponding letters indicate significant differences at $p<0.05$ by Duncan's test. ORAC ${ }_{\text {ROH. }}$, hydroxyl radical scavenging capacity. 
Table 2. Reducing capacity and metal chelating capacity of ginseng Jung Kwa extract

\begin{tabular}{ccc}
\hline Ginseng Jung $K w a^{1)}$ & $\begin{array}{c}\text { Reducing capacity } \\
(\text { Copper(I) ions, } \mu \mathrm{M})\end{array}$ & $\begin{array}{c}\text { Metal chelating capacity } \\
(\% \text { of control) }\end{array}$ \\
\hline GJK-3 & $2.10 \pm 0.17^{\mathrm{a}}$ & $46.99 \pm 1.11^{\mathrm{a}}$ \\
GJK-6 & $3.82 \pm 0.19^{\mathrm{b}}$ & $54.03 \pm 1.45^{\mathrm{ab}}$ \\
GJK-12 & $8.81 \pm 0.43^{\mathrm{c}}$ & $56.74 \pm 1.07^{\mathrm{b}}$ \\
\hline
\end{tabular}

The results represent the means \pm SD of values obtained from three experiments.

Different corresponding letters indicate significant differences at $p<0.05$ by Duncan's test.

${ }^{1)}$ GJK was made by different heat-processing time, GJK-3, GJK-6, and GJK-12.

and reducing capacity. However, these results differed from a previous study [27], which reported that the inhibition against hydroxyl radicals decreased with the increase in heat processing in a glucose-glycine model system. Further study to consider the effects of other components produced during heat processing of GJK may be needed.

\section{Cellular anti-oxidant capacity of GJK extract against AAPH-, $\mathrm{Cu}^{2+}-$, or $\mathrm{H}_{2} \mathrm{O}_{2}$ - induced oxidative stress in HepG2 cells}

A cellular anti-oxidant assay is a useful model for evaluating the anti-oxidant activity of dietary supplements and foods in cell culture, because it can reflect the cellular environment that occurs in vivo [28]. Other researchers have documented that HepG2 cells are a well-differentiated, transformed cell line for antioxidant studies [29] and yield consistent results with lower variation than other cell lines, including Caco-2 and RAW 264.7 cells [28].

The potential cytotoxicity of GJK extract was analyzed using the MTT assay. Over the concentration range tested, the GJK extract did not have a significant effect on cell viability (Fig. 3). The GJK extract concentration that corresponded to $90 \%$ cell viability was selected for subsequent assays.

GJK extract at a concentration of $1 \mathrm{mg} / \mathrm{mL}$ effectively reduced AAPH-induced oxidative stress in HepG2 cells in the order: GJK-12 (77.7\%)=GJK-6 (76.6\%) > GJK-3 extract (51.9\%) (Fig. 4). Fig. 5 shows that the oxidative stress induced by $\mathrm{Cu}^{2+}$ in HepG2 cells was scavenged by GJK extract in the order: GJK-12 (40.5\%)=GJK-6 (41.9 $\%)>$ GJK-3 extract (29.7\%). GJK-12 and GJK-6 extracts showed stronger cellular anti-oxidant capacity to scavenge the oxidative stress induced by AAPH or $\mathrm{Cu}^{2+}$ than the GJK-3 extract, but there were no significant differences between the GJK-12 and GJK-6 extracts. The anti-oxidant capacity of GJK extract to reduce the oxida-

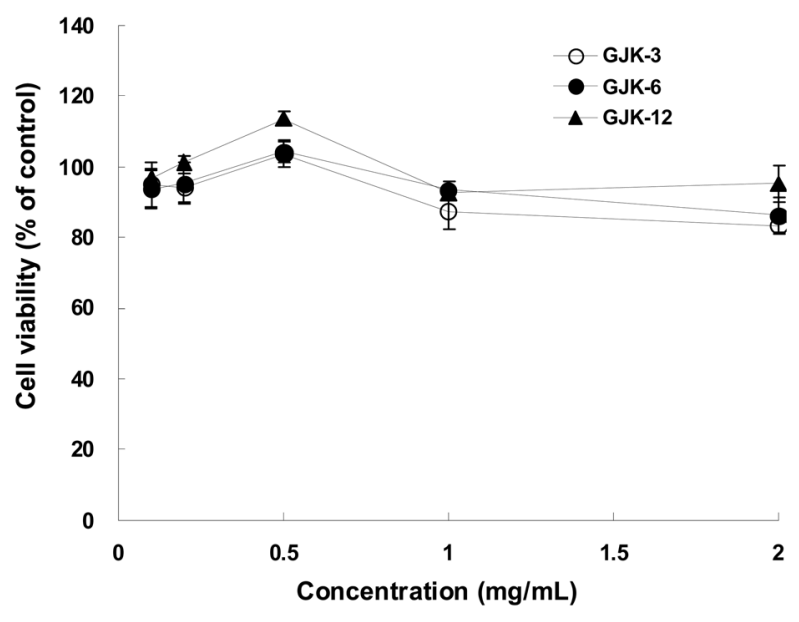

Fig. 3. Percentage viability of HepG2 cells exposed to different concentrations of GJK extract. GJK was made using different heat processing times: GJK-3, GJK-6, and GJK-12. Cell viability was examined by the MTT assay. Results are relative to control values and expressed as the mean $\pm S D$ for three individual experiments.

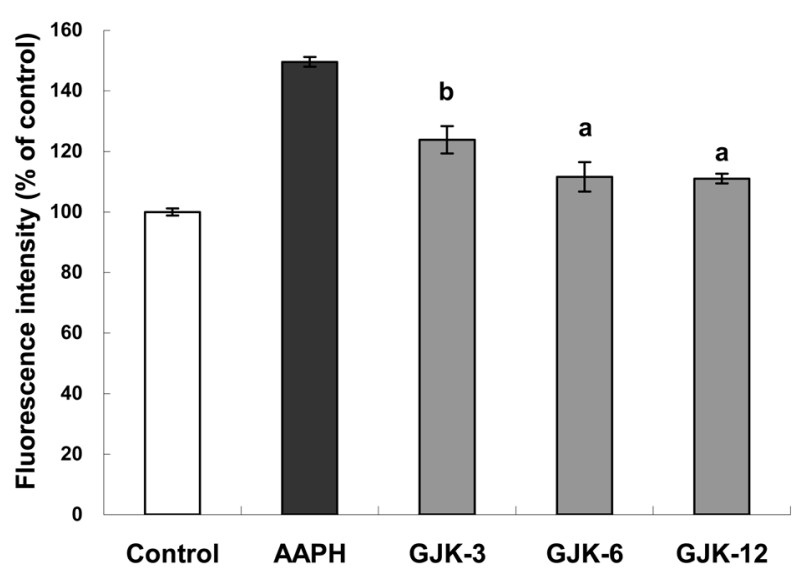

Fig. 4. Intracellular antioxidant capacity of ginseng Jung Kwa (GJK) extract against the oxidative stress generated by 2,2'-azobis (2-amidinopropane) dihydrochloride (AAPH) in HepG2 cells. GJK was made using different heat processing times: GJK-3, GJK-6, and GJK-12. The concentration of GJK extract applied to HepG2 cells was $1 \mathrm{mg} / \mathrm{mL}$. The results represent the mean $\pm S D$ of values obtained from three experiments. Different corresponding letters among samples indicate significant differences at $p<0.05$ by Duncan's test.

tive stress induced by $\mathrm{H}_{2} \mathrm{O}_{2}$, which is an important ROS to release hydroxyl radicals through the Fenton reaction, is shown in Fig. 6. The scavenging capacity of GJK extract against the oxidative stress caused by $\mathrm{H}_{2} \mathrm{O}_{2}$ increased in the order : GJK-12 (89.4\%)> GJK-6 (66.3\%) > GJK-3 $(41.0 \%)$, with the increase in heat processing time.

These results demonstrated that the cellular antioxidant capacity of GJK extract to reduce the oxidative stress induced by $\mathrm{AAPH}, \mathrm{Cu}^{2+}$, or $\mathrm{H}_{2} \mathrm{O}_{2}$ was positively correlated with the amount of total phenolic content. In turn, total phenolic content was proportional to 


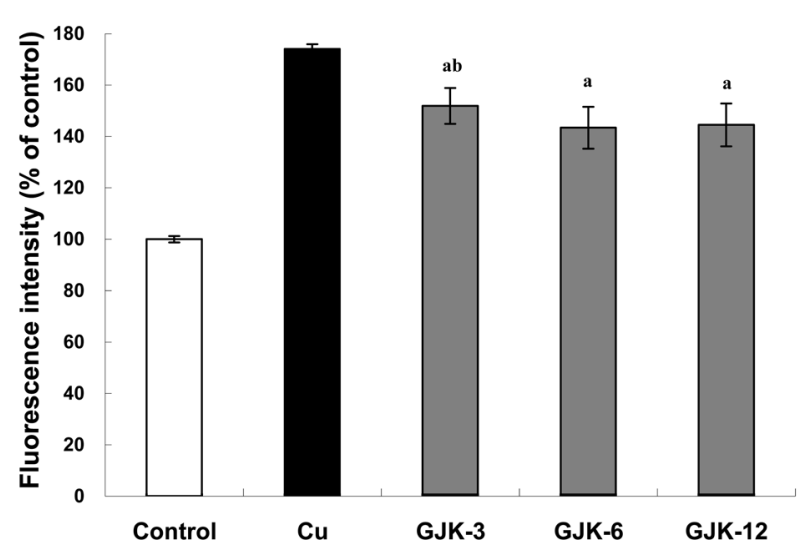

Fig. 5. Intracellular antioxidant capacity of GJK extract against oxidative stress generated by $\mathrm{Cu}^{2+}$ in $\mathrm{HepG} 2$ cells. GJK was made using different heat processing times: GJK-3, GJK-6, and GJK-12. The concentration of GJK extract applied to HepG2 cells was $1 \mathrm{mg} / \mathrm{mL}$. The results are presented as the mean $\pm \mathrm{SD}$ of values obtained from three measurements. Different corresponding letters among samples indicate significant differences at $p<0.05$ by Duncan's test.

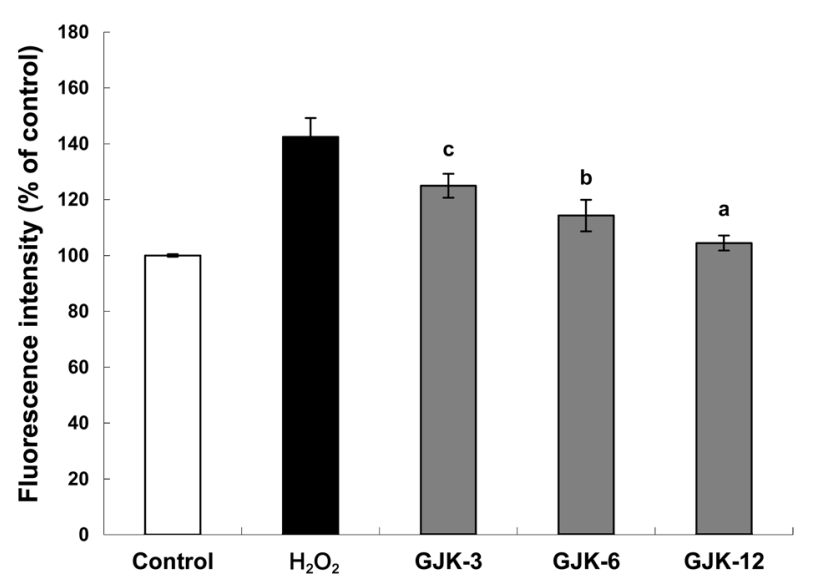

Fig. 6. Intracellular antioxidant capacity of GJK extract against oxidative stress generated by $\mathrm{H}_{2} \mathrm{O}_{2}$ in HepG2 cells. GJK was made using different heat processing times: GJK-3, GJK-6, and GJK-12. The concentration of GJK extract applied to HepG2 cells was $1 \mathrm{mg} / \mathrm{mL}$. The results are presented as the mean $\pm S D$ of values obtained from three measurements. Different corresponding letters among samples indicate significant differences at $p<0.05$ by Duncan's test.

the extent of heat processing. In a cellular model, the cellular antioxidant efficacy of phenolic compounds depends on two factors: the ability to penetrate the cellular membrane and the antioxidant activity inside the cells [30]. The total phenolic content of GJK extract was enhanced by increasing heat processing time. This result is consistent in previous studies [13,31] even though different heat processing methods were used. After these phenolic compounds in the GJK extract are formed as consequence of the heat processing used, they may be oxidized to more active forms [12]. Thus, the enhanced phenolic compounds of GJK extract pass readily through the cell membrane, so that higher cellular concentrations may result, contributing to protection against cellular oxidative stress induced by different ROS [30].

In conclusion, among the GJK extracts, GJK-12 extract had the highest total phenolic content and in vitro anti-oxidant capacity. The hydroxyl radical-scavenging activity of GJK-12 extract was stronger than those of GJK-3 and GJK-6 extracts, which was consistent with metal chelating activity and reducing capacity. In a cellular model, the GJK extract effectively reduced AAPH-, $\mathrm{Cu}^{2+}$ , or $\mathrm{H}_{2} \mathrm{O}_{2}$ - induced oxidative stress. GJK-12 and GJK-6 extracts had stronger cellular antioxidant capacity than GJK-3 extract. These results suggest that heat processing can contribute to the antioxidant capacity of GJK extract and the GJK extract may have the potential to be used as an effective dietary antioxidant to prevent oxidative stress-related conditions.

\section{ACKNOWLEDGEMENTS}

This study was supported by a research grant from Hannam University, Daejeon, Korea in 2010.

\section{REFERENCES}

1. Halliwell B, Aeschbach R, Loliger J, Aruoma OI. The characterization of antioxidants. Food Chem Toxicol 1995;33:601-617.

2. Trachootham D, Alexandre J, Huang P. Targeting cancer cells by ROS-mediated mechanisms: a radical therapeutic approach? Nat Rev Drug Discov 2009;8:579-591.

3. Lim JK, Kang HJ, Kang SN, Lee BY. Antioxidant and antimicrobial activities of various solvent fractions of fine ginseng root. Food Sci Biotechnol 2009;18:513-518.

4. Tchilian EZ, Zhelezarov IE, Hadjiivanova CI. Effect of ginsenoside $\mathrm{Rg} 1$ on insulin binding in mice liver and brain membranes. Phytother Res 1991;5:46-48.

5. Lee KS, Kim GH, Kim HH, Song MR, Kim MR. Quality characteristics of ginseng Jung Kwa and Jung Kwa solution on Jung Kwa process. J Korean Soc Food Sci Nutr 2009;38:587-593.

6. Paek JK, Kim JH, Yoon SJ. Quality characteristics of ginseng Jung Kwa after different soaking times in sugar syrup. Korean J Food Cookery Sci 2006;22:792-798.

7. Kim HJ, Jeong DS, Ju HG. The effect of honey concentration on the quality of honeyed ginseng in the process of manufacturing honeyed ginseng. Korean J Ginseng Sci 1985;9:128-134.

8. Cho EJ, Piao XL, Jang MH, Baek SH, Kim HY, Kang KS, 
Kwon SW, Park JH. The effect of steaming on the free amino acid contents and antioxidant activity of Panax ginseng. Food Chem 2008;107:876-882.

9. Kaneko H, Nakanishi K. Proof of the mysterious efficacy of ginseng: basic and clinical trials: clinical effects of medical ginseng, korean red ginseng: specifically, its antistress action for prevention of disease. J Pharmacol Sci 2004;95:158-162.

10. Keum YS, Park KK, Lee JM, Chun KS, Park JH, Lee SK, Kwon H, Surh YJ. Antioxidant and anti-tumor promoting activities of the methanol extract of heat-processed ginseng. Cancer Lett 2000;150:41-48.

11. Suzuki Y, Choi KJ, Uchida K, Ko SR, Sohn HJ, Park JD. Arginyl-fructosyl-glucose and arginyl-fructose, compounds related to browning reaction in the model system of steaming and heat-drying processes for the preparation of red ginseng. J Ginseng Res 2004;28:143-148.

12. Lee JW, Do JH. Current studies on browning reaction products and acidic polysaccharide in Korean red ginseng. J Ginseng Res 2006;30:41-48.

13. Kang KS, Yamabe N, Kim HY, Okamoto T, Sei Y, Yokozawa $\mathrm{T}$. Increase in the free radical scavenging activities of American ginseng by heat processing and its safety evaluation. J Ethnopharmacol 2007;113:225-232.

14. Moreno MI, Isla MI, Sampietro AR, Vattuone MA. Comparison of the free radical-scavenging activity of propolis from several regions of Argentina. J Ethnopharmacol 2000;71:109-114.

15. Kurihara H, Fukami H, Asami S, Toyoda Y, Nakai M, Shibata H, Yao XS. Effects of oolong tea on plasma antioxidative capacity in mice loaded with restraint stress assessed using the oxygen radical absorbance capacity (ORAC) assay. Biol Pharm Bull 2004;27:1093-1098.

16. Cao G, Sofic E, Prior RL. Antioxidant and prooxidant behavior of flavonoids: structure-activity relationships. Free Radic Biol Med 1997;22:749-760.

17. Argirova MD, Ortwerth BJ. Activation of protein-bound copper ions during early glycation: study on two proteins. Arch Biochem Biophys 2003;420:176-184.

18. Aruoma OI, Murcia A, Butler J, Halliwell B. Evaluation of the antioxidant and prooxidant actions of gallic acid and its derivatives. J Agric Food Chem 1993;41:18801885.

19. Lautraite S, Bigot-Lasserre D, Bars R, Carmichael N. Optimisation of cell-based assays for medium throughput screening of oxidative stress. Toxicol In Vitro 2003;17:207220.
20. Kang KS, Kim HY, Pyo JS, Yokozawa T. Increase in the free radical scavenging activity of ginseng by heatprocessing. Biol Pharm Bull 2006;29:750-754.

21. Cao G, Alessio HM, Cutler RG. Oxygen-radical absorbance capacity assay for antioxidants. Free Radic Biol Med 1993;14:303-311.

22. Prior RL, Hoang H, Gu L, Wu X, Bacchiocca M, Howard L, Hampsch-Woodill M, Huang D, Ou B, Jacob R. Assays for hydrophilic and lipophilic antioxidant capacity (oxygen radical absorbance capacity (ORAC(FL))) of plasma and other biological and food samples. J Agric Food Chem 2003;51:3273-3279.

23. Kim YC, Cho CW, Rhee YK, Yoo KM, Rho JH. Antioxidant activity of ginseng extracts prepared by enzyme and heat treatment. J Korean Soc Food Sci Nutr 2007;36:14821485.

24. Pastor N, Weinstein H, Jamison E, Brenowitz M. A detailed interpretation of $\mathrm{OH}$ radical footprints in a TBP-DNA complex reveals the role of dynamics in the mechanism of sequence-specific binding. J Mol Biol 2000;304:55-68.

25. Lee JS. Kim GN, Lee SH, Kim ES, Ha KS, Kwon YI, Jeong HS, Jang HD. In vitro and cellular antioxidant activity of arginyl-fructose and arginyl-fructosyl-glucose. Food Sci Biotechnol 2009;18:1505-1510.

26. Kim GN, Lee JS, Jang HD. In vitro and cellular antioxidant activity of a water extract of Saururus chinensis. Food Sci Biotechnol 2008;17:1332-1336.

27. Yoshimura Y, Iijima T, Watanabe T, Nakazawa H. Antioxidative effect of maillard reaction products using glucoseglycine model system. J Agric Food Chem 1997;45:41064109.

28. Wolfe KL, Kang X, He X, Dong M, Zhang Q, Liu RH. Cellular antioxidant activity of common fruits. J Agric Food Chem 2008;56:8418-8426.

29. Alia M, Mateos R, Ramos S, Lecumberri E, Bravo L, Goya L. Influence of quercetin and rutin on growth and antioxidant defense system of a human hepatoma cell line (HepG2). Eur J Nutr 2006;45:19-28.

30. Kim GN, Jung HM, Jang HD. Structure-activity relationship of citrus hydroxyflavanone glycosides and their aglycones against oxidative damage in HepG2 cells. J Clin Biochem Nutr 2008;43:508-511.

31. Kim KT, Yoo KM. Effect of hot water boiling and autoclaving on physicochemical properties of American ginseng (Panax quinquefolium L.). J Ginseng Res 2009;33:40-47. 